Original Investigation

Netrin-1 receptor-deficient mice show age-specific impairment in drug-induced locomotor hyperactivity but still self-administer methamphetamine

Jee Hyun Kim ${ }^{1}$, Doron Lavan ${ }^{1}$, Nicola Chen, Cecilia Flores, Helen Cooper, \& Andrew J. Lawrence*

1. These authors contributed equally to this work

* Corresponding author

Affiliations:

J. H. Kim, D. Lavan, N. Chen, A. J. Lawrence*

Florey Department of Neuroscience

University of Melbourne

Parkville 3010, VIC, Australia

*Email: andrewjl@unimelb.edu.au

Phone: +61-3-9035-6692

Fax: +6139348 1707

C. Flores

Department of Psychiatry

McGill University

Montreal, Quebec, Canada 


\section{H. Cooper}

Queensland Brain Institute

The University of Queensland

Brisbane 4072, QLD, Australia

Funded by National Health and Medical Research Council (NHMRC) Project Grant APP1022201 to AJL and JHK. AJL is an NHMRC PRF while JHK is an Australian Research Council DECRA Fellow. The Victorian Government's Operational Infrastructure Support Program is gratefully acknowledged. HMC was supported by a Queensland Government Smart Futures Fellowship. 


\section{Abstract}

Rationale The mesocorticolimbic dopamine system undergoes significant reorganization of neuronal connectivity and functional refinement during adolescence. DCC (deleted in colorectal cancer), a receptor for the guidance cue netrin-1, is involved in this reorganization. Previous studies have shown that adult mice with a heterozygous (het) loss-of-function mutation in DCC exhibit impairments in sensitization and conditioned place preference (CPP) to psychostimulants. However, the commonly abused psychostimulant methamphetamine $(\mathrm{METH})$ has not been assessed, and the role of DCC in drug selfadministration remains to be established. Objectives Using dcc het mice and wildtype (WT) littermates, we extended previous findings on $d c c$ haplodeficiency by examining selfadministration of METH in adult mice, including cue-induced drug seeking following abstinence. We also examined hyperactivity, sensitization and CPP to a METH-paired context in adult and adolescent mice. Results While adult $d c c$ het mice expressed largely similar METH selfadministration and cue-induced drug seeking as WT littermates, they failed to modulate responding according to dose of METH. Compared to WT, both adult and adolescent $d c c$ het mice expressed impaired locomotor hyperactivity to acute METH but nevertheless showed comparable behavioral sensitization. Conditioned hyperactivity increased with age in WT, but not dcc het, mice. Conclusions Impaired METH-induced hyperactivity and dose-related responding in adult $d c c$ het mice suggests that reduced DCC alters METH-related behaviors. Adolescence is identified as a vulnerable period during which impairment in hyperactivity due to reduced DCC can be overcome with repeated METH injections. Nevertheless, DCC appears to have a somewhat limited role in METH-consumption and seeking following abstinence. 


\section{Introduction}

Seeking rewards such as food and sex is essential for survival, however, it can lead to maladaptive behavior when expressed pervasively, manifesting as addiction. Drug addiction is a chronic, relapsing neurological disorder characterized by compulsive drug craving, seeking and use that persists despite serious adverse consequences (Kalivas and Volkow, 2005). Importantly, there is individual variability between drug users in their susceptibility to the effects of drugs (Kalivas, 2005), and animal studies modeling the Diagnostic and Statistical Manual of Mental Disorders (DSM-IV) criteria of addiction also report individual differences in mesocorticolimbic circuitry function (Deroche-Gamonet et al, 2004; Kasanetz et al, 2010, 2012). In particular, the mesocorticolimbic dopamine system is well-known for its importance in the consumption of natural rewards, and it is believed that drug use essentially 'highjacks' this system in the path to addiction (Kelley and Berridge, 2002).

The neurobiological mechanisms underlying individual vulnerability to addiction are yet to be fully elucidated. Genetic and environmental events occurring early in life may lead to abnormalities in the development of the mesocorticolimbic dopamine system, sensitizing its function later in life (Flores, 2011). How such early events might result in enduring changes in the function of mesocorticolimbic dopamine circuitry is unknown. One possible mechanism is alteration of the proteins involved in the organization of dopamine circuitry. Netrin-1 is a secreted guidance cue that attracts or repels growing neuronal processes through two main families of receptors. DCC (deleted in colorectal cancer) receptor is responsible for the role of attraction (Barallobre et al., 2005) and it is expressed in dopamine neurons (Manitt et al., 2010; Osborne et al., 2005). Critically, DCC is found in the brain from embryonic life and into adulthood, potentially enabling re-organization of mesocorticolimbic circuits during and following maturation (Livesey \& Hunt, 1997; Manitt et al., 2011; Osborne et al., 2005). Thus, mice deficient in $d c c$ (the gene responsible for the receptor DCC) have provided an 
opportunity to test the role of netrin-1 receptors in mesocorticolimbic dopamine circuitry and its related behaviors. Mice haploinsufficient for $d c c$ have lower levels of DCC protein throughout the brain (Flores et al., 2005). Heterozygous $d c c$ mice are used because homozygous knockout mice die at birth (Fazeli et al., 1997). Furthermore, varying DCC levels rather than deleting the receptor altogether provides a model with greater ethological validity (Srour et al., 2010; Flores, 2011).

Consistent with the potential role of DCC in dopamine-related behaviors, in vivo microdialysis studies in adult $d c c$ het mice have shown a reduction in amphetamine-induced dopamine release in the nucleus accumbens (NAc) but an increase of dopamine concentrations in the medial prefrontal cortex (mPFC) before and after amphetamine exposure (Flores et al., 2005). These results are interesting in light of previous studies that report repeated stimulant use can cause a decrease in dopamine signaling in the mPFC (Salo et al., 2009) and ultimately increase dopamine outflow into the striatum (Evans et al., 2006; Volkow et al., 2006), which parallels the development of behavioral sensitization (Ventura et al., 2004). Indeed, adult $d c c$ het mice exhibit significantly attenuated hyperactivity in response to an initial amphetamine injection as well as attenuated behavioral sensitization when treated repeatedly compared to wildtype (WT) littermates (Flores et al., 2005; Grant et al., 2007; Yetnikoff et al., 2010). Using the conditioned place preference (CPP) model, Grant et al. (2007) also reported that adult $d c c$ het mice failed to acquire a preference to a context paired with a moderate dose $(2.2 \mathrm{mg} / \mathrm{kg})$ of amphetamine whilst acquiring CPP with a high dose $(4.4 \mathrm{mg} / \mathrm{kg})$, whereas WT littermates acquired CPP at both doses. These results show diminished sensitivity to the conditioned rewarding properties of amphetamine in $d c c$ het mice, suggesting a role of DCC in mediating drug-related behaviors.

The present study, therefore, further investigated the role of DCC in behaviors relevant to addiction using a commonly abused psychostimulant methamphetamine (METH). 
METH is an extremely popular illegal substance of abuse particularly among adolescents; second only to the use of cannabis with an estimated global prevalence of $0.4 \%$ (Marshall \& Werb, 2010). METH has similar pharmacokinetic and pharmacodynamic properties to amphetamine (Melega et al., 1995); however, while evoked NAc dopamine levels are similar for both amphetamine and METH, amphetamine administration results in larger extracellular levels of dopamine in the MPFC than does METH due to amphetamine's superior ability to block dopamine reuptake and clearance, leading to some differences in behavior caused by the two drugs (Shoblock et al., 2003). Thus, findings on DCC with amphetamine may be due to its differential ability to block dopamine clearance in $\mathrm{mPFC}$ and the role of DCC may not generalize to other drugs.

We first examined the behavioral phenotype of adult $d c c$ het mice using the intravenous self-administration paradigm followed by post-abstinence cue-induced drugseeking because a role of DCC in drug self-administration has not been previously investigated. Whilst behavioral sensitization has been posited by some as a neurobiological process underlying human addiction (Robinson \& Berridge, 1993), recent findings have provided initial evidence that propensity to sensitize or learn a place preference is not correlated with a propensity to reinstate drug-seeking (Ahmed \& Cador, 2005; Brown et al., 2010; Lenoir \& Ahmed, 2007). Thus, it is necessary and important to examine the role of DCC in a model of relapse following a period of self-administration, especially considering that relapse subsequent to successful detoxification or protracted abstinence remains high and forms the most challenging aspect and a central hallmark of addiction (McLellan et al., 2000). We also investigated behavioral sensitization and CPP in adult and adolescent $d c c$ het mice and their WT littermates using METH. Grant et al. (2007) demonstrated that in contrast to adult $d c c$ het mice, juvenile and adolescent $d c c$ het mice showed comparable acute hyperactivity and development of sensitization in response to amphetamine as their WT 
littermates (Grant et al., 2009; Yetnikoff et al., 2011). These results suggest that reduced DCC receptors may protect against drug-induced behaviors after, but not before, adolescence. Consistent with this idea dopaminergic innervation to the mPFC continues to develop into adulthood (Benes et al., 2000; Flores, 2011; Kalsbeek, 1988; Rosenberg \& Lewis, 1995). However, the ability of adolescent $d c c$ het mice to learn CPP remains untested. If it is the case that adolescent $d c c$ het mice display CPP comparable to their WT littermates, it would highlight adolescence as a vulnerable period to drug abuse regardless of DCC levels.

\section{MATERIALS AND METHODS}

\section{Animals}

Adolescent male $d c c$ het and WT mice bred on a C57B1/6 background at the University of Queensland were used [the fully backcrossed C57B1/6 strain was obtained from Prof Linda Richards (Queensland Brain Institutes)]. The original 129sv x C57B1/6 strain was provided by Dr Marc Tessier-Lavigne (Keino-Masu et al, 1996). Pups were weaned at postnatal day (P) $21 \pm 1$ and housed in cages with same sex littermates. Adult mice were P105 $( \pm 30)$ and adolescents P30 ( \pm 2$)$ on day 1 of any experiment. For conditioned place preference (CPP) experiments, mice were housed together with littermates on a 12 hour light/dark cycle (lights on at $7 \mathrm{am})$. For the intravenous self-administration experiment, mice were singly-housed on a 12 hour reverse light/dark cycle (lights on at $7 \mathrm{pm}$ ). Housing was in standard mouse boxes with access to water and mouse chow ad libitum.

\section{PCR}

Genotypes were unknown during experimentation and validated after completion of each experiment. Mice genotypes were validated using Polymerase Chain Reaction (PCR). DNA from tail samples was extracted using the REDExtract-N-AmpTM Tissue PCR Kit (Sigma). The following forward and reverse primers (Geneworks, Australia) were used: 


\section{5'-TCCTCGTGCTTTACGGTATC-3'}

\section{5'-GGCCATTGAGGTTCCTTT-3'}

\section{5'-AAGACGACCACACGCGAG-3'}

\section{Surgery}

In order to allow the mice to intravenously self-administer METH, catheters were implanted into the left jugular vein as described previously (Madsen et al., 2012). Mice were anesthetized with isoflurane (1.5\%-2\%) and injected with $0.1 \mathrm{ml}$ of meloxicam $(5 \mathrm{mg} / \mathrm{kg}$, i.p.), for pain relief and to prevent inflammation. The catheter was flushed with heparinized saline with antibiotic $(90 \mathrm{U} / \mathrm{ml}$ heparin, $0.03 \mathrm{~mL}$ neomycin sulfate $4 \mathrm{mg} / \mathrm{mL})$ to prevent infections and a small amount of blood drawn back through the line to test the patency of the catheter. Mice were then allowed at least 48 hours to fully recover before beginning intravenous-self administration. Catheters were flushed twice daily, immediately prior to each session with $0.02 \mathrm{ml}$ of $10 \mathrm{U}$ heparinized saline with antibiotic and immediately after each session with $0.02 \mathrm{ml}$ of $90 \mathrm{U}$ heparinized saline. At the conclusion of the experiment catheters were tested for patency with $0.02 \mathrm{ml}$ of a ketamine $(15 \mathrm{mg} / \mathrm{ml}$; Sigma). Sign of lost muscle tone within $3 \mathrm{~s}$ of ketamine infusion was regarded as intact patency. One WT mouse and one $d c c$ het mouse failed the patency test and were excluded from all analyses.

\section{Operant Self-Administration}

The ceiling, back wall and door of each operant chamber (Med Associates Inc, VT, USA) was made of clear Perspex, while the side walls consisted of aluminum channels to hold modular components. The floor was covered with a grid consisting stainless steel rods set above a catch pan. Two retractable levers were located $20 \mathrm{~cm}$ apart on one side wall. A stimulus light was located immediately above the active lever.

In order to shape the mice with the operant task, mice were first trained to lever press for a $5 \mu 1$ delivery of a $10 \%$ sucrose solution into a receptacle as described previously (Madsen et 
al., 2012; Brown et al., 2009). A drop of vanilla essence was placed below the active lever for the duration of the experiment functioning as a stimulus discriminative cue (S+). Reward delivery also coincided with illumination of the stimulus light functioning as a conditioned stimulus (CS+). A fixed ratio 1 (FR1) reinforcement schedule was used in which each active lever press resulted in one reward delivery. Following sucrose training, mice underwent jugular vein catheterization surgery as described above.

Methamphetamine intravenous-self administration (IVSA) sessions were two hours daily on FR1. Depression of the active lever resulted in the intravenous infusion of METH $(20 \mu \mathrm{L})$ coupled with a light conditioned stimulus (CS+) above the lever. In order to prevent overdose there was a 10 second time out period subsequent to each infusion during which active lever presses resulted in no outcome and the maximum drug infusions per session was set to 100 . Based on previous data from our laboratory (Chesworth et al., in press) a 'moderate' dose of $3 \mu \mathrm{g} / \mathrm{kg} /$ per infusion was used for the first six days followed by a lower dose $(1 \mu \mathrm{g} / \mathrm{kg})$ and a higher dose $(10 \mu \mathrm{g} / \mathrm{kg})$ for three days each. FR1 was followed by one day of Progressive Ratio (PR), tested at the final dose $(10 \mu \mathrm{g} / \mathrm{kg})$. The PR schedule consisted of an initial infusion that required a single lever press with each subsequent infusion requiring exponentially more effort (lever presses needed for each subsequent infusion: 1, 3, 9, 13, 16, 18, 20, 22 etc.). Previous studies suggest that a two-hour session provides reliable information regarding the mouse's motivation to acquire drug (Brown, et al. 2009; Soria et al., 2006). 3 WT and 3 dcc het mice were only tested at the $3 \mu \mathrm{g} / \mathrm{kg}$ dose throughout the experiment. Therefore, the PR and dose-response data analysis excluded these mice.

Following the last IVSA session, mice received forced abstinence for a period of three weeks in their home cages, after which cue-induced drug-seeking was measured. This was a one hour session during which the stimulus discriminative odor cue was present $(\mathrm{S}+)$ and the CS illuminated with each active lever press (CS+) but no reward was delivered. This allowed 
for the assessment of drug-seeking behavior without the confounding effect of the drug (Brown et al., 2009; Madsen et al., 2012).

\section{Conditioned Place Preference}

The CPP apparatus (Lafayette Instruments, Indiana, USA) consisted of two main conditioning compartments with differences in visual and tactile cues, separated by a 'neutral' compartment. The light intensity of the conditioning compartments and central compartment were 80 lux and 380 lux, respectively. In every session, infrared sensors recorded distance travelled (cm) and time spent (s) in each compartment (Brown et al., 2010). Each experimental session ran for 30 minutes. Mice were brought into the experimental room half an hour before each session for acclimatization. On day 1 at $3 \mathrm{pm}$ ( \pm 30 mins), mice were intraperitoneally (i.p.) injected with saline, placed in the central compartment and given free access to the entire apparatus. This allowed for measurement of their baseline preference before conditioning. Allocation of the METH-paired chamber was random and unbiased. For conditioning on days 2-5, mice were given an injection (i.p.) of saline at 9 am ( \pm 30 mins) and METH $(2 \mathrm{mg} / \mathrm{kg}$ or $1 \mathrm{mg} / \mathrm{kg})$ at $3 \mathrm{pm}( \pm 30 \mathrm{mins})$ and were immediately confined into one of the two conditioning compartments. Injection volume was always $10 \mathrm{ml} / \mathrm{kg}$. For test on day six, mice were again placed into the central compartment at $3 \mathrm{pm}( \pm 30 \mathrm{mins})$, and given free access to the entire apparatus, without any injection. Data were recorded using Motor Monitor software (Kinder Scientific, CA, USA).

\section{Statistical analyses}

To examine the effect of genotype and dose on METH self-administration, a mixed-design two-way repeated measures (RM) analysis of variance (ANOVA) was performed on total number of daily infusions. Comparison of PR breakpoint and cue-induced drug seeking postabstinence between genotypes was examined using an independent means two-tailed t-test. CPP data were analyzed using a mixed-design two-way RM ANOVA on comparing 
genotypes and preference for METH-paired context at baseline and at test. Locomotor data were similarly examined using a mixed-design RM ANOVA comparing genotype and locomotor activity in response to METH and saline. A two-way between subjects ANOVA was used to examine the collapsed conditioned hyperactivity data. For significant interactions, appropriate post-hoc t-tests were performed. Differences were deemed statistically significant if $p<0.05$.

\section{Results}

Experiment 1: Adult $d c c$ het mice exhibit comparable METH self-administration and seeking after abstinence to WT littermates

A two-way mixed-design RM ANOVA of active lever responses during sucrose training showed a significant main effect of Day $(\mathrm{F}(7,144)=18.3, p<0.05)$ with no effect of Genotype ( $\mathrm{n}=9 \mathrm{WT} ; \mathrm{n}=11 \mathrm{het})$ or interaction (largest $\mathrm{F}<1)$ (data not shown). That is, all mice increased responding for sucrose across days but there was no effect of genotype.

For METH self-administration, the number of infusions at each dose was analyzed the same way as sucrose. At the initial dose of $3 \mu \mathrm{g} / \mathrm{kg}$, both genotypes showed similar METH self-administration as indicated by a main effect of Day $(\mathrm{F}(5,90)=3.8, p<0.05)$ but no effect of Genotype $(\mathrm{F}(1,18)=1.1, p>0.05)$ or interaction $(\mathrm{F}<1)$ (Fig.1a). When the dose was lowered to $1 \mu \mathrm{g} / \mathrm{kg}$ there were neither main effects nor an interaction $(F \mathrm{~s}<1)$. When the dose was increased to $10 \mu \mathrm{g} / \mathrm{kg}$ there were again no significant effects (largest $\mathrm{F}=1.4, p>0.05$ ). Discrimination between the active and inactive lever was generally above $70 \%$, and never below $60 \%$, and there were no genotype differences in the number of inactive lever presses at any dose (biggest $\mathrm{F}=1.2$ ) (Figure $1 \mathrm{~b})$. 

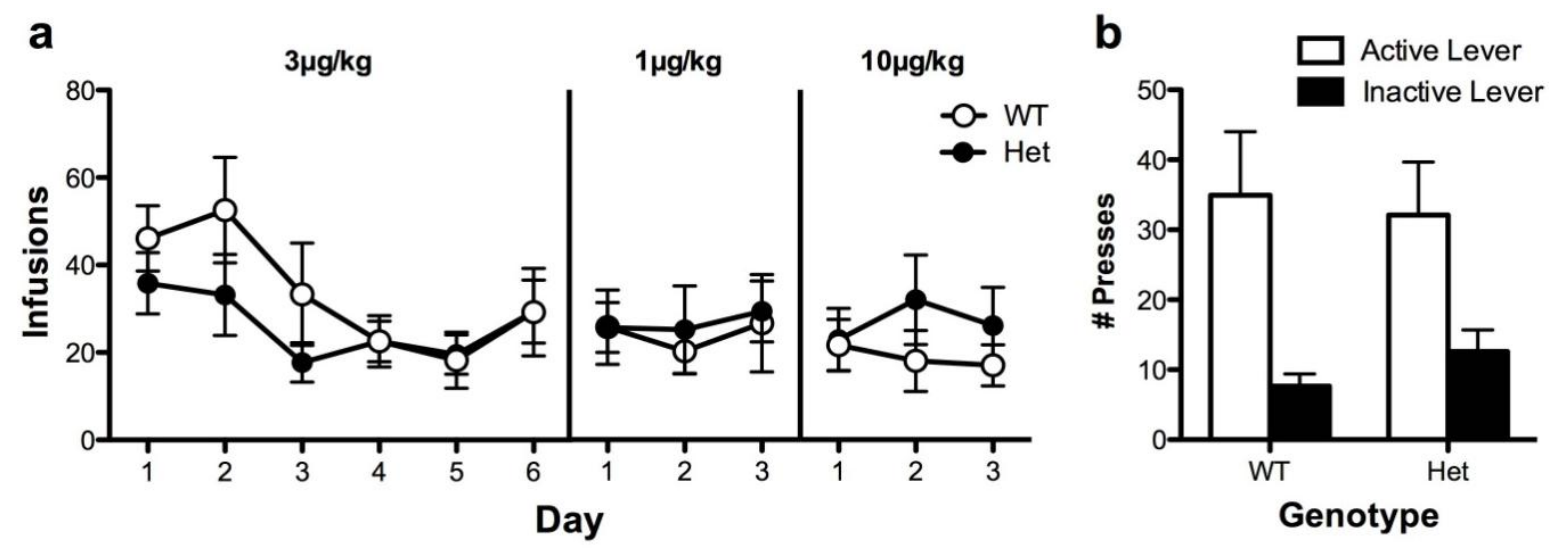

Fig. 1. Intravenous self-administration of METH on FR1 schedule. a. Number of METH infusions for all doses across days. There were no differences between the genotypes. b. Number of active and inactive lever presses averaged across all doses (last 3 days of the initial dose was used to reduce confound from sucrose training). There were no differences between the genotypes. WT and het indicate wildtype $(n=9)$ and heterozygote $(n=11)$ respectively.

The average number of infusions at each dose was then examined for each genotype to determine whether the ability to dynamically regulate self-administration to changing doses was mediated by DCC. Only the mice that received all 3 different doses were analyzed. Additionally, the last three days of the intermediate $(3 \mu \mathrm{g} / \mathrm{kg})$ dose were analyzed as this corresponded to stable self-administration following acquisition. A two-way mixed-design RM ANOVA revealed no effect of Dose $(\mathrm{F}<1)$, Genotype $(\mathrm{F}<1)$, nor overall interaction $(\mathrm{F}(2,24)=1.7, p>0.05)$. To specifically examine whether mice altered drug intake based on dose, we additionally analyzed by within-subjects quadratic contrast ANOVA using the same RM factor (dose) and between factor (genotype). Interestingly, even with a low sample population, there was a strong trend towards Dose $\mathrm{x}$ Genotype quadratic interaction $(\mathrm{F}(1,12)$ $=4.6, p=0.054)$, suggesting that WT regulated intake of METH when dose was changed whereas $d c c$ het mice did not (Fig. 2a). Note that doses are plotted in the temporal sequence experienced by the mice. 
a

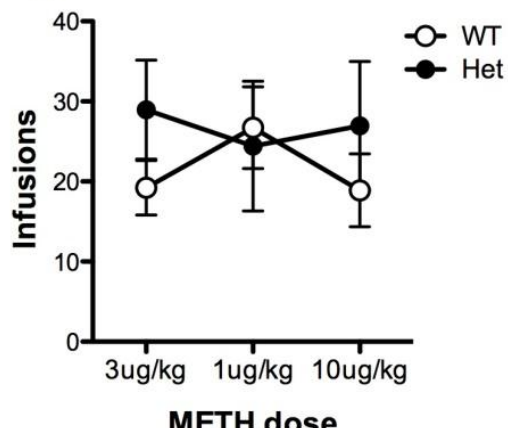

b

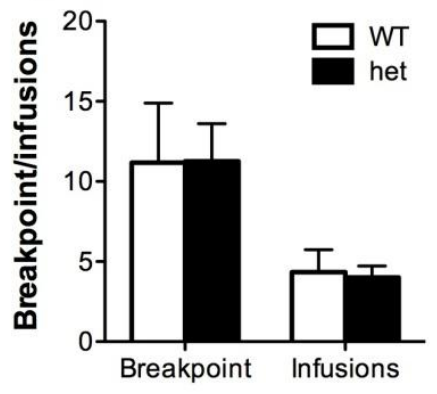

C

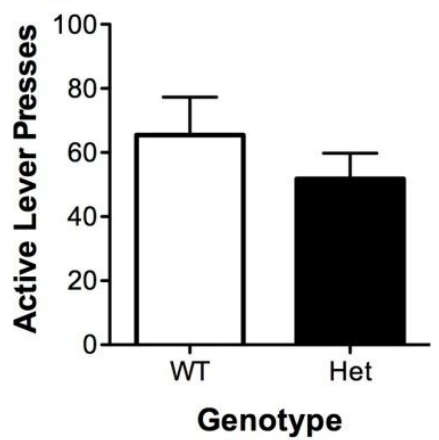

Fig. 2. a. Dose-response curve for both genotypes. WT and het indicate wildtype $(n=6)$ and heterozygote $(n=8)$ respectively. WT mice displayed a trend towards a significant quadratic function in response to different doses of METH, which was not observed in dcc het mice. $\mathbf{b}$. Progressive Ratio schedule of reinforcement for both genotypes $(10 \mu \mathrm{g} / \mathrm{kg})$. No differences between the genotypes were observed for either breakpoint or the number of infusions. WT $(n=6)$ and het $(n=8)$. c. Number of active lever presses during cue-induced drug-seeking test following three weeks of abstinence. There were no genotype effects. WT $(n=9)$ and het $(\mathrm{n}=11)$.

An independent means two-tailed t-tests showed that the breakpoint and infusions during PR for WT and $d c c$ het mice was not significantly different $(t s<1)$ (Fig. 2b). Similar analyses found no effect of genotype on cue-induced drug seeking post abstinence $(t<1)$ (Fig. 2c). Inactive lever presses did not differ for both PR and cue-induced drug-seeking test (biggest $t=1.3$; data not shown).

\section{Experiment 2: Adult $d c c$ het mice show impaired hyperactivity to METH that persists}

\section{across multiple injections}

We first determined METH-induced hyperactivity by comparing total distance travelled (i.e., locomotion) during saline and METH sessions using a mixed-design RM ANOVA ( $\mathrm{n}=12$ per genotype). On day one of the conditioning phase, all adult mice showed METH-induced acute hyperactivity as indicated by the significant main effect of Drug $(F(1,22)=137.0, p<$ 0.05). There was no main effect of Genotype $(\mathrm{F}(1,22)=3.1, p>0.05)$, however, there was a 
significant Drug x Genotype interaction $(F(1,22)=4.4, p<0.05)$. Post-hoc analyses indicated that the acute effect of first exposure to METH was greater in WT than hets $(t(22)=2.1, \mathrm{p}<$ 0.05), whilst saline had no differential effects $(t<1)$ (Fig. 3a). The significant Drug $x$ Genotype interaction was still present by conditioning day $4(\mathrm{~F}(1,22)=4.9, p<0.05)$, with WT displaying a greater response to METH than het mice $(\mathrm{t}(22)=2.8, \mathrm{p}<0.05)$, indicating that adult $d c c$ het mice continued to exhibit impaired hyperactivity to METH compared to WT (Fig. 3b). A three-way mixed-design RM ANOVA across all days of METH exposure revealed a significant main effect of Drug $(F(1,22)=331.2, p<0.05)$, no effect of Days $(\mathrm{F}<$ 1) and a significant interaction between Drug x Days $(\mathrm{F}(3,66)=23.9, p<0.05)$, indicating that METH-induced hyperactivity increased across days. However, there was no significant interaction between Genotype, Drug and Day $(\mathrm{F}(3,66)=1.4, p>0.05)$ (Fig. 3b).
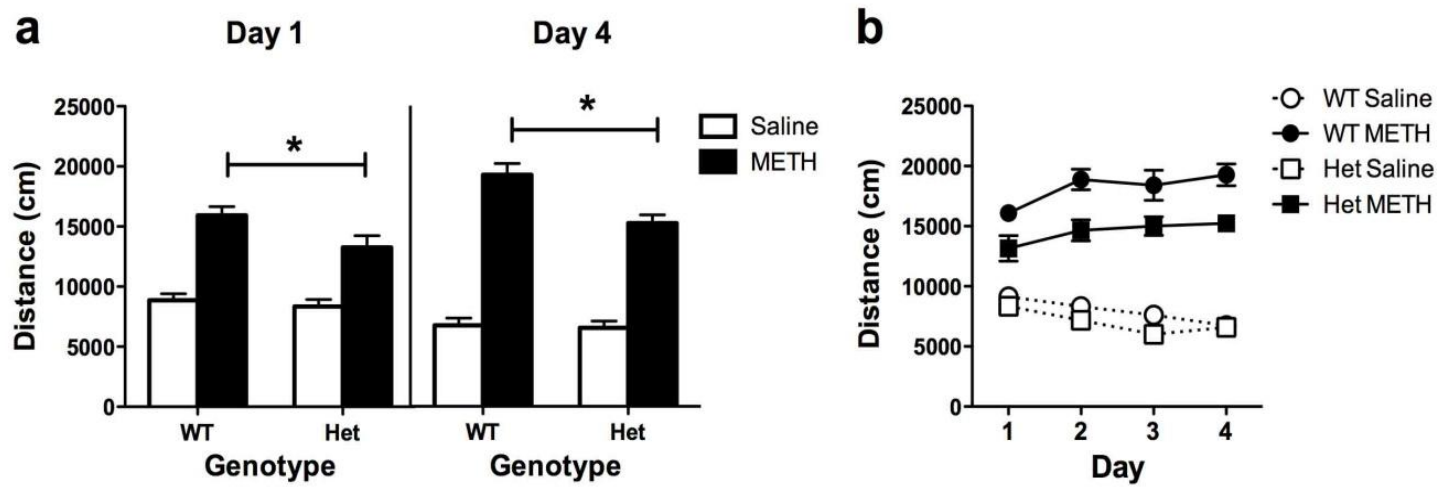

Fig. 3. Adult locomotor activity $(\mathrm{n}=12$ per genotype). Total distance travelled following injection of saline or METH (2mg/kg i.p.) a. on day one and day four; b. and across 4 days. * indicates a significant difference between WT and het mice following METH injections, $\mathrm{p}$ $<0.05$. The acute effect of first exposure to METH was greater in WT than het mice, and this effect was still present by conditioning day 4. METH-induced hyperactivity increased across days for both genotypes.

Conditioned place preference for the METH paired chamber was calculated by dividing time spent in that chamber by the combined time spent in saline and METH chambers at test [i.e., $\mathrm{CPP}$ score $=\mathrm{METH} /(\mathrm{METH}+$ saline $)]$. A two-way mixed-design $\mathrm{RM}$ ANOVA revealed a main effect of Session $(\mathrm{F}(1,22)=14.3, p<0.05)$. However, there was no 
main effect of Genotype nor an interaction (Fs $<1)$ (Fig. 4a). This result suggests that the ability to acquire CPP using $2 \mathrm{mg} / \mathrm{kg}$ of METH is intact in adult $d c c$ het mice. Hence, we replicated the experiment in a new cohort of mice using a lower conditioning dose of METH $(1 \mathrm{mg} / \mathrm{kg}$ ) because Grant et al. (2007) reported the emergence of a CPP phenotype in adult dcc het mice with moderate, but not high dose amphetamine. When $1 \mathrm{mg} / \mathrm{kg}$ METH was used, RM ANOVA revealed a trend towards Session $(\mathrm{F}(1,16)=3.9, p=0.067)$, but no significant effect of Genotype $(\mathrm{F}<1)$ nor Session x Genotype interaction $(\mathrm{F}(1,16)=1.8, p=0.2)$. To confirm whether WT littermates could acquire CPP using $1 \mathrm{mg} / \mathrm{kg}$ METH, we performed pairwise t-tests across session per genotype (Fig. 4b). WT displayed a significant increase in the preference score to METH-paired chamber $(\mathrm{t}(10)=3.4, \mathrm{p}<0.05)$ whereas het mice did $\operatorname{not}(\mathrm{t}<1)$.

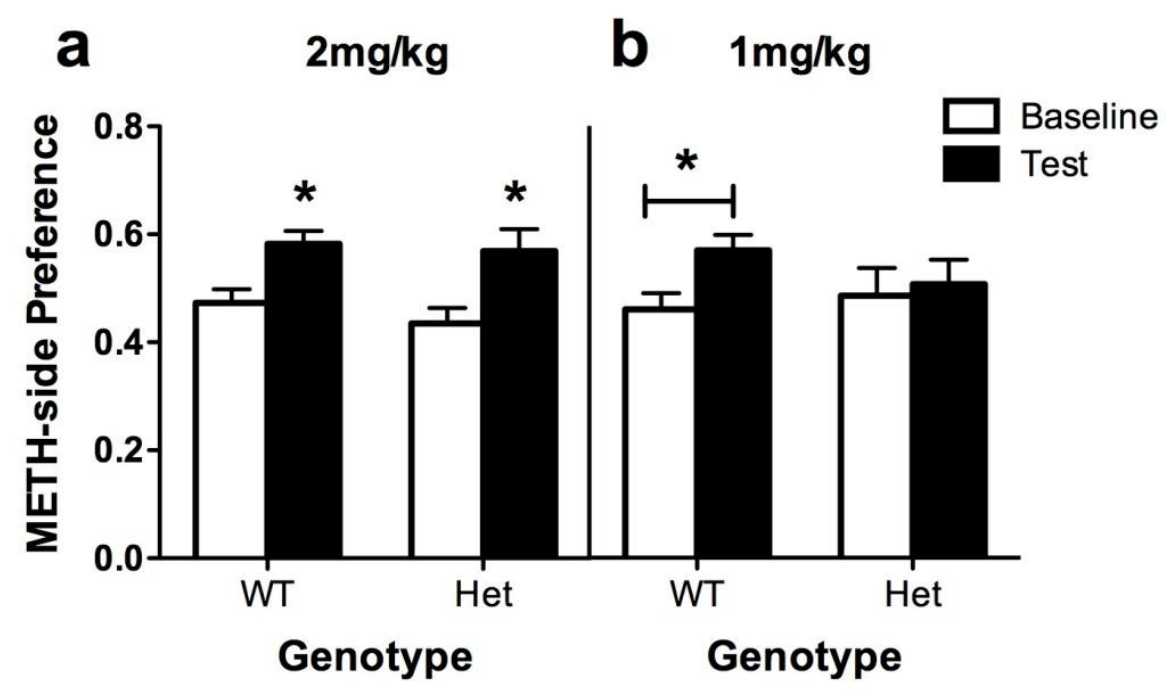

Fig. 4. a. Conditioned place preference (CPP) to METH $(2 \mathrm{mg} / \mathrm{kg})$ increased similarly compared to baseline across genotype in adult mice $(n=12$ per genotype). * indicates a significant difference of the test data compared to baseline, $\mathrm{p}<0.05$. b. CPP to a low dose of METH $(1 \mathrm{mg} / \mathrm{kg})$. Only WT mice displayed an increase in METH-side preference compared to the baseline. WT $(n=11)$ and het $(n=7) . *$ indicates a significant difference of the test data compared to baseline in WT mice, $\mathrm{p}<0.05$. 
Experiment 3: Adolescent $d c c$ het mice show impaired hyperactivity to METH that recovers across multiple injections

On day one of the conditioning phase, adolescents ( $n=11$ per genotype) showed METHinduced acute hyperactivity as indicated by the significant main effect of Drug $(F(1,20)=$ $12.7, p<0.05)$. There was no effect of Genotype $(\mathrm{F}(1,20)=1.8, p>0.05)$ but there was a significant Drug x Genotype interaction $(F(1,20)=7.5, p<0.05)$. Post-hoc tests indicated that the acute effect of first exposure to METH was greater in WT than hets $(\mathrm{t}(20)=2.3, \mathrm{p}<$ 0.05), whilst saline had no differential effects $(\mathrm{t}<1)$ (Fig. 5a). Unlike adult mice, this difference was only present on the first day of METH injection, by the second day and onwards there was no difference in locomotor activity between the two genotypes (biggest $\mathrm{F}(1,20)=2.05, p>0.05$; see Fig. 5a for the final METH injection on conditioning day 4). Analysis across days revealed a significant main effect of Days $(\mathrm{F}(3,60)=18.3, p<0.05)$, Drug $(\mathrm{F}(1,20)=127.5, p<0.05)$ and a significant interaction between Days $x$ Drug $(\mathrm{F}(3,60)$ $=38.1, p<0.05)$, but there was no interaction between Days, Drug and Genotype $(\mathrm{F}(3,60)=$ $1.3, p>0.05)$, indicating that METH induced hyperactivity increased across days similarly for both genotypes (Fig. 5b).
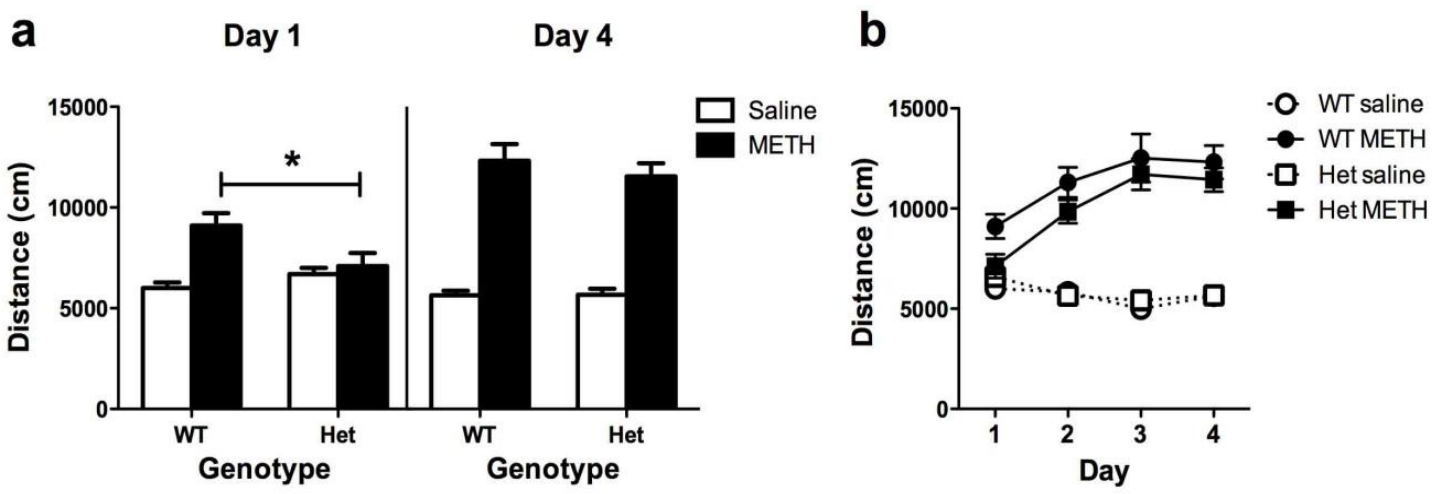

Fig. 5. Adolescent locomotor activity ( $n=11$ per genotype). Total distance travelled following injection of saline or METH (2mg/kg i.p.) a. on day one and day four; b. and across 4 days. The acute effect of first exposure to METH was greater in WT than het mice; however, this effect was limited to day 1. METH-induced hyperactivity increased across days for both 
genotypes. * indicates a significant difference between WT and het mice following METH injections on day $1, \mathrm{p}<0.05$.

CPP did not differ between genotypes. Analyses revealed time spent in the METH paired chamber was greater on test day than on baseline day as indicated by a main effect of Session $(\mathrm{F}(1,20)=31.27, p<0.05)$. There was no effect of Genotype $(\mathrm{F}<1)$ nor an interaction $(\mathrm{F}(1,20)=1.3, p>0.05)($ Fig. 6a) .

a

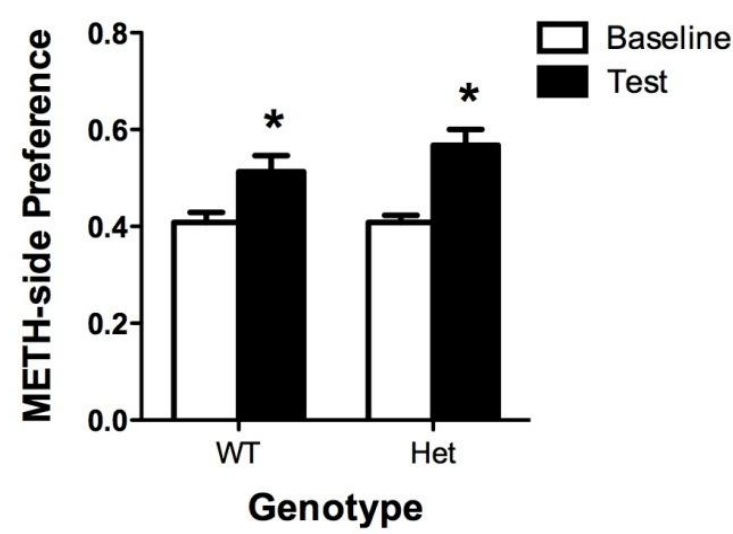

b

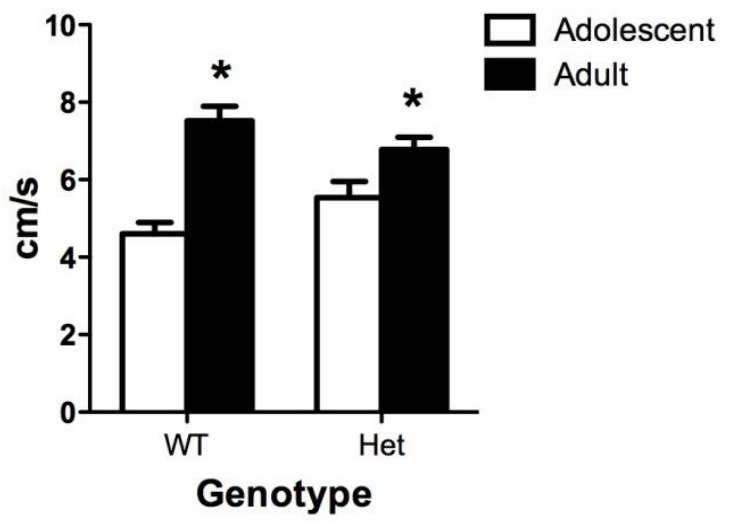

Fig. 6. a. Conditioned place preference to METH $(2 \mathrm{mg} / \mathrm{kg})$ increased similarly compared to baseline across genotype in adolescent mice $(n=11$ per genotype). * indicates a significant difference of the test data compared to baseline, $\mathrm{p}<0.05$. b. Speed $(\mathrm{cm} / \mathrm{second})$ in the METH-paired chamber on test day as a measure of conditioned hyperactivity. Conditioned hyperactivity was greater in adults $(n=12$ per genotype) that adolescents $(n=11$ per genotype), an effect that was greater in wildtypes than heterozygotes. * indicates a significant difference of the adult speeds compared to adolescent speeds, $\mathrm{p}<0.05$.

\section{Conditioned Hyperactivity}

To examine age-related changes in conditioned hyperactivity, speed $(\mathrm{cm} / \mathrm{s})$ of the mice in the 2mg/kg METH-paired chamber during test session (drug free) in experiments 2 and 3 were collapsed and analyzed. There was a main effect of Age $(\mathrm{F}(1,42)=34.3, p<0.05)$, no effect of Genotype $(\mathrm{F}<1)$, but a significant Age $\mathrm{x}$ Genotype interaction $(\mathrm{F}(1,42)=8.0, p<0.05)$ indicating that WT mice displayed a greater increase in conditioned hyperactivity post- 
adolescence than $d c c$ het mice (Fig. 6b). Post-hoc independent samples t-tests indicates that both WT and $d c c$ het adult mice displayed a significantly higher hyperactivity compared to their adolescent counterparts $(p s<0.05)$.

\section{Discussion}

The present study extends previous work examining the role of the netrin-1 receptor DCC in addiction-related behaviors. Adult $d c c$ het mice self-administered METH and exhibited comparable cue-induced drug seeking post-abstinence as WT littermates. There was however a strong trend $(p=0.054)$ towards an interaction of the dose-response function across genotype, suggesting that WT mice effectively titrated their number of METH infusions related to dose, whereas $d c c$ het mice did not. At a low dose of METH (1mg/kg), adult $d c c$ het mice did not develop CPP. At a higher dose of METH $(2 \mathrm{mg} / \mathrm{kg})$ both adult and adolescent mice developed comparable METH-induced CPP across genotypes. Furthermore, both adult and adolescent $d c c$ het mice showed impaired acute locomotor hyperactivity to METH. Lastly, there was a developmental dissociation in conditioned hyperactivity to the METHpaired context; WT mice displayed a significant age-associated increase whereas $d c c$ het mice did not.

\section{Self-Administration}

We show here for the first time that there were no differences between $d c c$ het and WT littermates in lever pressing for sucrose. This is important, as it demonstrates that instrumental learning for a reward was intact in the het mice. The mesocorticolimbic dopamine pathways are responsible for the mediation of natural rewards as well as drugs of abuse (Kelley \& Berridge, 2002). Thus, it could plausibly be expected that DCC deficiencies would lead to attenuated sucrose reinforcement. Therefore, the ability of hets to acquire the 
sucrose-reinforced response clearly shows that they are able to form action-outcome associations.

Here we show that the DCC gene is not necessary for METH self-administration, since $d c c$ het mice showed essentially comparable behavior as WT littermates. Based on the previous findings with amphetamine (Grant et al, 2007), it was expected that het mice would show a rightward shift in the dose response during METH self-administration. Specifically, we hypothesized that $d c c$ het mice would show an attenuated response for the lower dose, with a possible augmented response for the higher dose compared to WT littermates. Although there were no significant differences between the genotypes at any given dose, WT littermates showed clear evidence of titration of METH self-administration as a function of dose changes, a pattern not observed in $d c c$ het mice. That is, $d c c$ het mice failed to modulate the level of self-administration according to dose and maintained similar levels of responding throughout the experiment. This result suggests that dcc haplodeficiency leads to altered sensitivity to dose changes during METH self-administration, and that reduced DCC receptor levels during adulthood may lead to altered drug abuse patterns. Notably, in WT mice, the lowest dose of METH supported the greatest number of actual drug infusions, which declined as dose was subsequently increased. In contrast, het mice showed similar numbers of drug infusions across all three doses. This may suggest that $d c c$ het mice are relatively insensitive to the acute aversive after effects of METH compared to WT mice, or the in vivo half life of METH may be reduced in het compared to WT littermates. A more definitive answer requires assessment over an increased range of doses to generate complete curves for each genotype.

The progressive ratio schedule is believed to be a more sensitive measure of the reinforcing efficacy of the drug, and it is particularly useful following training with a FR regimen (Arnold \& Roberts, 1997). In our study, both genotypes showed a similar break point when PR was tested. Additionally, both genotypes showed comparable cue-induced 
drug seeking following 3 weeks of abstinence. These findings indicate that the motivation to consume methamphetamine and the ability to retrieve cue-drug associations are intact in $d c c$ het mice. Such results contrast with the previously demonstrated importance of DCC in druginduced sensitization and locomotor hyperactivity, supporting the idea that the mechanisms mediating sensitization are not entirely the same as those mediating drug-seeking (Ahmed \& Cador, 2005; Brown et al., 2010; Lenoir \& Ahmed, 2007).

\section{Conditioned Place Preference and Locomotor Hyperactivity}

Consistent to findings on amphetamine-induced CPP that showed a rightward shift in the dose response for heterozygous mice (Grant et al., 2007), compared to their WT littermates $d c c$ het adult mice showed an impairment in exhibiting CPP when the dose of METH was low $(1 \mathrm{mg} / \mathrm{kg})$ but displayed a similar preference when the dose of METH was increased ( $2 \mathrm{mg} / \mathrm{kg})$. CPP for METH in mice has been established using doses ranging from $1-5 \mathrm{mg} / \mathrm{kg}$ and (Chen, et al., 2003), hence, our 'higher' dose of METH (2 mg/kg) should be regarded as moderate, and it is noteworthy that adult $d c c$ het mice acquired CPP as well as WT littermates. Furthermore, examination of the locomotor activity shows clear genotype differences at the $2 \mathrm{mg} / \mathrm{kg}$ dose of METH. That is, adult hets showed significant attenuation of locomotor activity in response to $2 \mathrm{mg} / \mathrm{kg}$ METH throughout the CPP conditioning phase. This attenuation of METH-induced locomotor activity in adult $d c c$ het mice is similar to the previously demonstrated attenuation of amphetamine-induced locomotion (Flores et al., 2005; Grant et al., 2007; Yetnikoff et al., 2010) and suggests a parallel role for DCC in both METH and amphetamine-related increase in dopamine release in the striatal complex. These findings highlight that acute drug-induced hyperactivity does not necessarily correlate with the acquisition of CPP, which is consistent with previous findings that showed no relationship between CPP and locomotion in inbred C57BL/6J and DBA/2J mice using 4 different doses 
of cocaine or morphine (Orsini et al., 2005). Taken together, the present results show reduced DCC leads to impaired acute METH-induced hyperactivity but does not lead to overall deficits in learning or memory - Pavlovian conditioning is clearly intact. This is important, as addiction is often conceptualized as a pathological form of learning (Berke \& Hyman, 2000). Furthermore, these results confirm our self-administration results that DCC deficient mice are able to experience the positively reinforcing effects of the drug and learn associations between a cue and a drug.

As with the adult het mice, adolescent het mice showed attenuated METH-induced locomotor hyperactivity. However, unlike adult mice this effect was only observed during the first conditioning exposure to METH when the mice were drug naive. In response to repeated METH injections, adolescent $d c c$ het and WT mice showed comparable locomotor hyperactivity. This was not the case for the adults where $d c c$ het mice showed attenuated METH-induced locomotor activity on each challenge. This attenuated acute METH-induced hyperactivity displayed by adolescent dcc het mice is consistent with the previous report using amphetamine (Yetnikoff et al., 2013). In that study, locomotor activity was measured during 90 minute sessions and reported an overall trend of reduced acute responding to amphetamine in adolescent $d c c$ het mice compared to WT mice even across repeated injections (Yetnikoff et al., 2013). In contrast, the present study examined locomotor activity over 30 minute sessions capturing the very initial response to METH. Taken together, it appears that locomotor differences between adolescent $d c c$ het and WT mice may emerge at slightly different times depending on the type of psychostimulant injection and the length of time measured.

\section{Conditioned hyperactivity}


The ability of the METH-paired chamber to elicit hyperactivity even when a mouse is in a drug-free state is known as conditioned hyperactivity. Although controversial, there seems to be strong evidence that this effect relies on classic associative learning processes (Rauhut \& Bialecki, 2011). While overall there was a significant increase in conditioned hyperactivity in adult mice than in adolescent mice, this effect was greater in WT compared to $d c c$ het mice. Conditioned hyperactivity relies on both the presence of METH-induced hyperactivity and intact associative learning processes responsible for associating this hyperactivity with its context during conditioning sessions. Given that the $d c c$ het mice in the present study successfully established a CPP to the same extent as WT mice using $2 \mathrm{mg} / \mathrm{kg}$ METH, differences in conditioned hyperactivity between genotypes are likely due to differences in METH-induced locomotor hyperactivity. That is, while the ability of METH to induce locomotor hyperactivity increases with the age in WT mice, the ability of METH to induce locomotor hyperactivity in $d c c$ het mice remains unchanged at the moderate dose.

The mPFC, unlike the NAc, is a structure that continues to develop through adolescence and into early adulthood (Voorn et al., 1988; Rosenberg \& Lewis, 1995). Indeed it has been shown that dopamine innervation of $\mathrm{mPFC}$ in rats continues up until post-natal day 60 (Kalsbeek et al., 2008). Dopamine in the PFC can ultimately control NAc dopamine levels (Ventura et al., 2004). Dopamine release in striatal regions such as the NAc is a critical determinant for acute drug-induced hyperactivity, which may explain the difference in METH-induced conditioned hyperactivity between adolescent and adult mice. Interestingly, the dopamine innervation to the $\mathrm{mPFC}$ undergoes reorganization during adolescence and exhibits, in adulthood, an increased span of mPFC dopamine terminals as well as increased extracellular levels of dopamine (Mannit et al, 2011). Thus, drug-induced dopamine release in the NAc remains low in adult $d c c$ het mice as opposed to their WT littermates suggesting a 
mechanism by which reduced DCC may actually confer "protection" to the effects of stimulant drugs in adulthood.

The findings from conditioned hyperactivity, exhibited during a drug-free CPP test session, suggest that mice that have developed with lower DCC are relatively protected against certain dopamine-related behavioral alterations through differential dopamine organization in the mPFC during maturation. If vulnerability to addiction does in fact involve DCC-mediated signaling, the differences in conditioned hyperactivity suggest risk factors would have their greatest impact early in adolescence. While environmental factors during adulthood could act via DCC to reorganize dopamine pathways, reorganization of a more stabilized brain would be relatively more difficult. During adolescence, on the other hand, when the $\mathrm{mPFC}$ is maturing and in a labile state, the potential of environmental factors to act via DCC to enhance or impair this stabilization is greatly increased. Thus, risk factors known to be associated with substance dependence would be far more influential during adolescence. Furthermore, the use of psychostimulants during adolescence could alter DCC levels in dopamine neurons, eliminating any existing protection that an individual with previously low levels of DCC may have had (Yetnikoff et al, 2011). The influence of stimulant drug use in adolescents with previously low levels of DCC is important as DCC heterozygosity has recently been identified among the human population (Srour et al., 2010). The identification of adolescence as a potentially sensitive time for developing substance dependence should be considered when discussing the use of prescription drugs such as methylphenidate, often prescribed to children with attention deficit hyperactive disorder (Leonard et al., 2004).

In conclusion, we have extended the previously demonstrated importance of DCC in amphetamine- and cocaine-induced locomotor hyperactivity using METH. Notably, the effects of $d c c$ haplodeficiency on drug-induced locomotor changes did not correlate with the 
ability to acquire CPP to a METH-paired context. Despite the previously demonstrated importance of DCC in amphetamine-and cocaine-induced sensitization, DCC was shown to have a limited role in METH self-administration and cue-conditioned seeking. This supports previous findings that the mechanisms mediating sensitization are not entirely the same as those mediating relapse (Ahmed \& Cador, 2005; Brown et al., 2010; Lenoir \& Ahmed, 2007). Nevertheless, since there are overlaps in the neurocircuitry of sensitization and relapse-like behaviors (Steketee \& Kalivas, 2011) further work is needed to understand this dissociation with greater clarity. Subsequent studies on large cohorts could divide the mice into groups based on whether or not they display addict-like behaviors (e.g. difficulty stopping drug use, high motivation to obtain the drug, continued drug use despite negative consequences). DCC could then be measured in each group to more accurately assess the correlation between DCC and addiction-related behaviors. 


\section{References}

Adams CL, Short JL, Lawrence AJ (2010) Cue-conditioned alcohol seeking in rats following abstinence: involvement of metabotropic glutamate 5 receptors $\mathrm{Br} \mathrm{J}$ Pharmacol 159: $534-542$

Ahmed SH, Cador M (2005) Dissociation of psychomotor sensitization from compulsive cocaine consumption. Neuropsychopharmacology 31:563-571.

Arnold JM, Roberts D (1997) A critique of fixed and progressive ratio schedules used to examine the neural substrates of drug reinforcement. Pharmacol Biochem Behav 53:441-447.

Benes, F. M., Taylor, J. B., \& Cunningham, M. C. (2000). Convergence and plasticity of monoaminergic systems in the medial prefrontal cortex during the postnatal period: implications for the development of psychopathology. Cerebral Cortex, 10(10), 10141027.

Barallobre MJ, Pascual M, Del Rio JA, Soriano E (2005) The Netrin family of guidance factors: emphasis on Netrin-1 signalling. Brain Res Rev 49:22-47.

Berke JD, Hyman SE (2000) Addiction, dopamine, and the molecular mechanisms of memory. Neuron 25:515-532.

Brown RM, Short JL, Cowen MS, Ledent C, Lawrence AJ (2009) A differential role for the adenosine A2A receptor in opiate reinforcement vs opiate-seeking behavior. Neuropsychopharmacology 34:844-856.

Brown RM, Short JL, Lawrence AJ (2010) Identification of brain nuclei implicated in cocaine-primed reinstatement of conditioned place preference: a behavior dissociable from sensitization. PLoS One 5:1-13.

Chen H, Yang Y, Yeh T, Cherng C, Hsu H, Hsiao S, Yu L (2003). Methamphetamine-induced conditioned place preference is facilitated by estradiol pretreatment in female mice. Chinese J Physiol 46:169-174.

Chesworth RM, Brown RM, Kim JH, Lawrence AJ (2013). The metabotropic glutamate 5 receptor modulates extinction and reinstatement of methamphetamine-seeking in mice. PLoS One, in press.

Deroche-Gamonet V, Belin D, Piazza P-V (2004). Evidence for addiction-like behavior in the rat. Science 305:1014-1017.

Evans, A. H., Pavese, N., Lawrence, A. D., Tai, Y. F., Appel, S., Doder, M., ... \& Piccini, P. (2006). Compulsive drug use linked to sensitized ventral striatal dopamine transmission. Annals Neurol 59:852-858.

Fazeli, A., Dickinson, S. L., Hermistonf, M. L., Tigne, R. V., SteenI, R. G., Small, C. G., . . . Rayburnf, H. (1997). Phenotype of mice lacking functional Deleted in colorectal cancer \{Dcc) gene. PROBE, 1:1-8.

Flores, C. (2011). Role of netrin-1 in the organization and function of the mesocorticolimbic dopamine system. J Psychiatry Neurosci, 36:296-310.

Flores, C., Manitt, C., Rodaros, D., Thompson, K. M., Rajabi, H., Luk, K. C., . . Kennedy, T. E. (2005). Netrin receptor deficient mice exhibit functional reorganization of dopaminergic systems and do not sensitize to amphetamine. Mol Psych, 10 : 606-612.

Grant, A., Hoops, D., Labelle-Dumais, C., Prevost, M., Rajabi, H., Kolb, B., . . . Flores, C. (2007). Netrin-1 receptor-deficient mice show enhanced mesocortical dopamine transmission and blunted behavioral responses to amphetamine. Eur J Neurosci 26: 3215-3228.

Grant, A., Speed, Z., Labelle-Dumais, C., \& Flores, C. (2009). Post-pubertal emergence of a dopamine phenotype in netrin-1 receptor-deficient mice. Eur J Neurosci 30: 1318-1328. 
Kalivas PW (2005). How do we determine which drug-induced neuroplastic changes are important? Nat Neurosci 8: 1440-1441.

Kalivas PW, Volkow ND (2005). The neural basis of addiction: a pathology of motivation and choice. Am J Psychiatry 162:1403-1413.

Kalsbeek A, Voorn P, Buijs RM, Pool CW, Uylings HBM (1988) Development of the dopaminergic innervation in the prefrontal cortex of the rat. J Comp Neurol 269:58-72.

Kasanetz F, Deroche-Gamonet V, Berson N, Balado E, Lafourcade M, Manzoni O, et al (2010) Transition to addiction is associated with a persistent impairment in synaptic plasticity. Science 328:1709-1712.

Kasanetz F, Lafourcade M, Deroche-Gamonet V, Revest JM, Berson N, Balado E, et al. (in press). Prefrontal synaptic markers of cocaine addiction-like behavior in rats. Mol Psych. doi: $10.1038 / \mathrm{mp} .2012 .59$.

Keino-Masu K, Masu M, Hinck L, Leonardo ED, Chan S-Y, Culotti JG, Tessier-Lavigne M. (1997) Deleted in colorectal cancer (DCC) encodes a netrin receptor. Cell 87:175-185.

Kelley AE, Berridge KC (2002). The neuroscience of natural rewards: relevance to addictive drugs. J Neurosci 22: 3306-3311.

Leonard BE, McCartan D, White J, King DJ (2004) Methylphenidate: a review of its neuropharmacological, neuropsychological and adverse clinical effects. Human Psychopharmacol: Clin Exp 19:151-180.

Lenoir M, Ahmed SH (2006) Heroin-induced reinstatement is specific to compulsive heroin use and dissociable from heroin reward and sensitization. Neuropsychopharmacology 32:616-624.

Livesey F, Hunt S (1997) Netrin and netrin receptor expression in the embryonic mammalian nervous system suggests roles in retinal, striatal, nigral, and cerebellar development. Mol Cellular Neurosci 8:417-429.

Madsen HB, Brown RM, Short JL, Lawrence AJ (2012). Investigation of the neuroanatomical substrates of reward seeking following protracted abstinence in mice. $\mathrm{J}$ Physiol 590:2427-2442.

Manitt C, Labelle-Dumais C, Eng C, Grant A, Mimee A, Stroh T, \& Flores C. (2010). Peripubertal emergence of UNC-5 homologue expression by dopamine neurons in rodents. PloS One, 5(7).

Manitt C, Mimee A, Eng C, Pokinko M, Stroh T, Cooper HM et al (2011) The netrin receptor DCC is required in the pubertal organization of mesocortical dopamine circuitry. $\mathrm{J}$ Neurosci 31:8381-8394.

Marshall BD, Werb D (2010). Health outcomes associated with methamphetamine use among young people: a systematic review. Addiction 105:991-1002.

McLellan AT, Lewis DC, O'Brien CP, Kleber HD (2000). Drug dependence, a chronic medical illness. JAMA 284:1689-1695.

Melega WP, Williams, AE, Schmitz DA, DiStefano EW, Cho AK (1995) Pharmacokinetic and pharmacodynamic analysis of the actions of D-amphetamine and D-methamphetamine on the dopamine terminal. J Pharmacol Exp Ther 274: 90-96.

Orsini C, Bonito-Oliva A, Conversi D, Cabib S (2005) Susceptibility to conditioned place preference induced by addictive drugs in mice of the C57BL/6 and DBA/2 inbred strains. Psychopharmacol 181: 327-336.

Osborne PB, Halliday GM, Cooper HM, \& Keast JR (2005). Localization of immunoreactivity for deleted in colorectal cancer (DCC), the receptor for the guidance factor netrin-1, in ventral tier dopamine projection pathways in adult rodents. Neuroscience, 131:671-681.

Peters J, Kalivas PW, Quirk GJ (2009) Extinction circuits for fear and addiction overlap in prefrontal cortex. Learn Mem 16:279-288. 
Rauhut AS, Bialecki V (2011). Development and persistence of methamphetamine-conditioned hyperactivity in Swiss-Webster mice. Behav Pharmacol 22:228-238.

Reichel CM, Bevins RA (2009) Forced abstinence model of relapse to study pharmacological treatments of substance use disorder. Current Drug Abuse Rev 2:184.

Robinson TE, Berridge KC (1993) The neural basis of drug craving: an incentive-sensitization theory of addiction. Brain Res Rev 18:247.

Rosenberg DR, Lewis DA (1995) Postnatal maturation of the dopaminergic innervation of monkey prefrontal and motor cortices: a tyrosine hydroxylase immunohistochemical analysis. J Comp Neurol 358:383-400.

Salo, R., Ursu, S., Buonocore, M. H., Leamon, M. H., \& Carter, C. (2009). Impaired prefrontal cortical function and disrupted adaptive cognitive control in methamphetamine abusers: a functional magnetic resonance imaging study. Biol Psych, 65: 706-709.

Shaham Y, Shalev U, Lu L, de Wit H, Stewart J (2003) The reinstatement model of drug relapse: history, methodology and major findings. Psychopharmacol 168:3-20.

Shoblock JR, Sullivan EB, Maisonneuve IM, Glick SD (2003). Neurochemical and behavioral differences between d-methamphetamine and d-amphetamine in rats. Psychopharmacology 165:359-369.

Soria G, Castañé A, Ledent C, Parmentier M, Maldonado R, Valverde O (2005) The lack of A2A adenosine receptors diminishes the reinforcing efficacy of cocaine. Neuropsychopharmacology 31:978-987.

Srour M, Rivière JB, Pham JM, Dubé MP, Girard S, Morin S, Dion PA, Asselin G, Rochefort D, Hince P, Diab S, Sharafaddinzadeh N, Chouinard S, Théoret H, Charron F, Rouleau GA (2010) Mutations in DCC cause congenital mirror movements. Science 328:592.

Steketee, J. D., \& Kalivas, P. W. (2011). Drug wanting: behavioral sensitization and relapse to drug-seeking behavior. Pharmacological Reviews, 63(2), 348-365.

Ventura R, Alcaro A, Cabib S, Conversi D, Mandolesi L, Puglisi-Allegra S (2004) Dopamine in the medial prefrontal cortex controls genotype-dependent effects of amphetamine on mesoaccumbens dopamine release and locomotion. Neuropsychopharmacology 29:72-80.

Volkow, N. D., Wang, G. J., Telang, F., Fowler, J. S., Logan, J., Childress, A. R., ... \& Wong, C. (2006). Cocaine cues and dopamine in dorsal striatum: mechanism of craving in cocaine addiction. J Neurosci, 26: 6583-6588.

Voorn, P., Kalsbeek, A., Jorritsma-Byham, B., \& Groenewegen, H. J. (1988). The pre-and postnatal development of the dopaminergic cell groups in the ventral mesencephalon and the dopaminergic innervation of the striatum of the rat. Neuroscience, 25(3), 857-887.

Yetnikoff L, Almey A, Arvanitogiannis A, Flores C (2011) Abolition of the behavioral phenotype of adult netrin-1 receptor deficient mice by exposure to amphetamine during the juvenile period. Psychopharmacology 217:505-514.

Yetnikoff L, Eng C, Benning S, Flores C (2010). Netrin-1 receptor in the ventral tegmental area is required for sensitization to amphetamine. Eur J Neurosci 31:1292-1302.

Yetnikoff L, Pokinko M, Arvanitogiannis A, Flores C (in press). Adolescence: a time of transition for the phenotype of $d c c$ heterozygous mice. Psychopharmacology. DOI 10.1007/s00213-013-3083-z. 

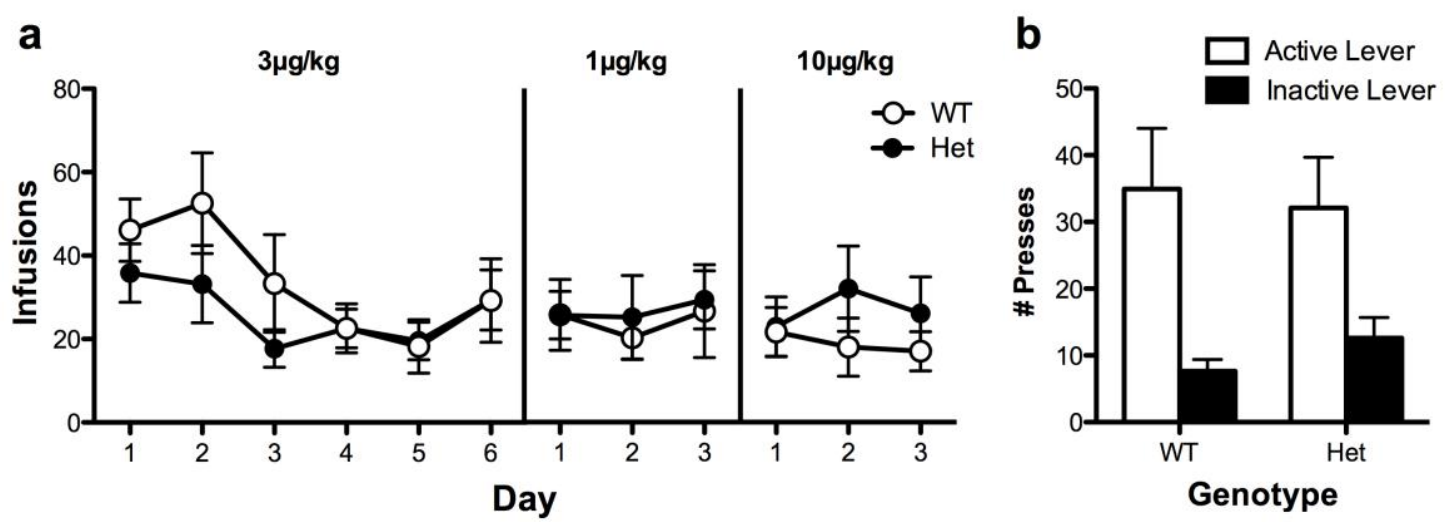
a

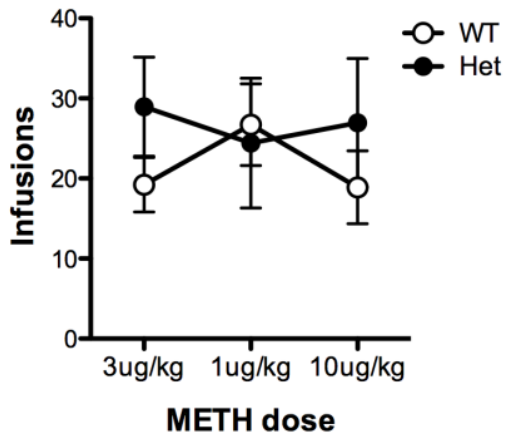

b

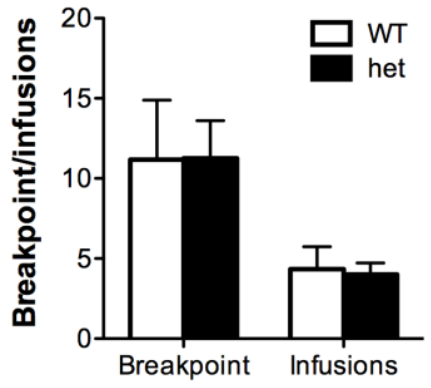

C

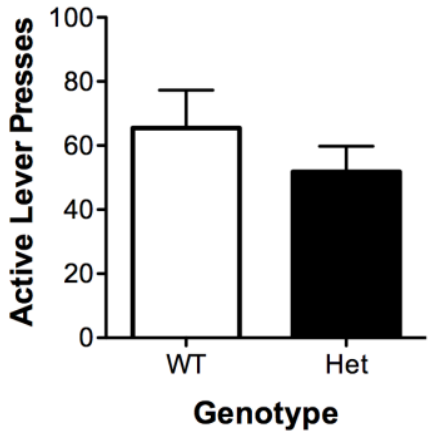


a

Day 1

Day 4

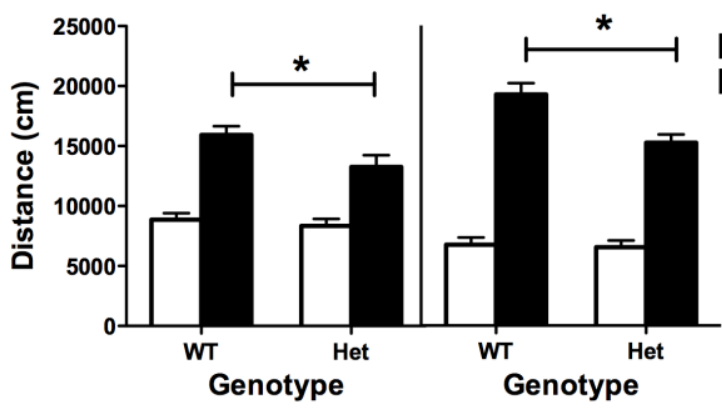

b

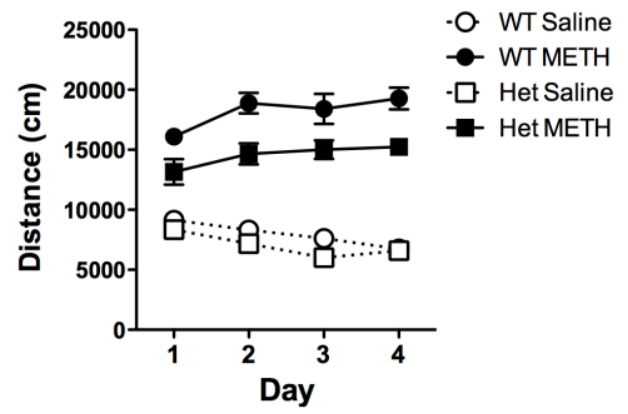




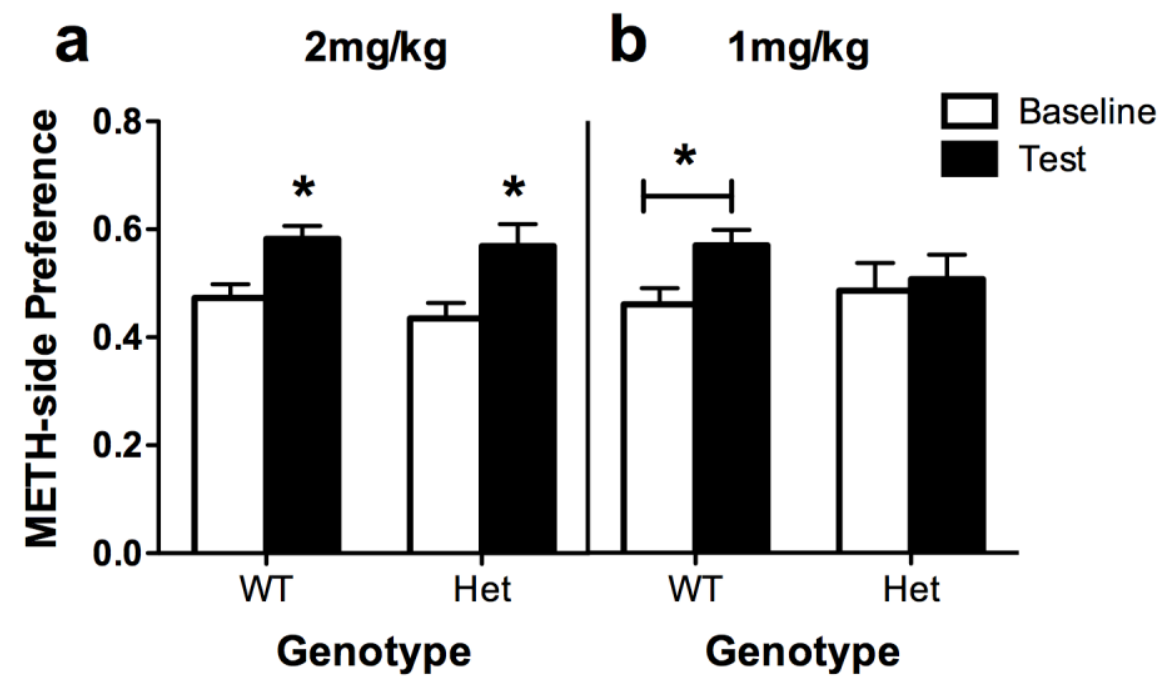



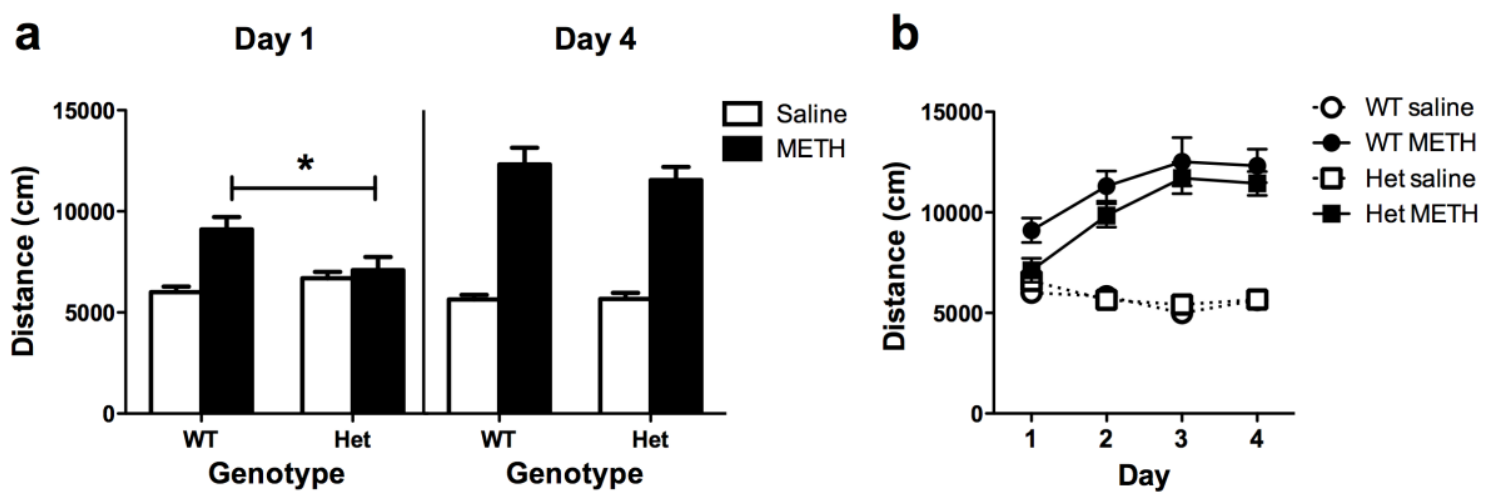
34

a

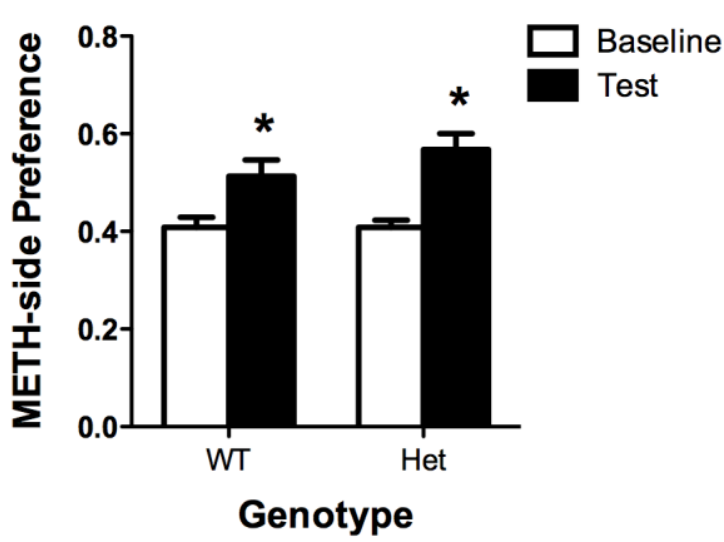

b

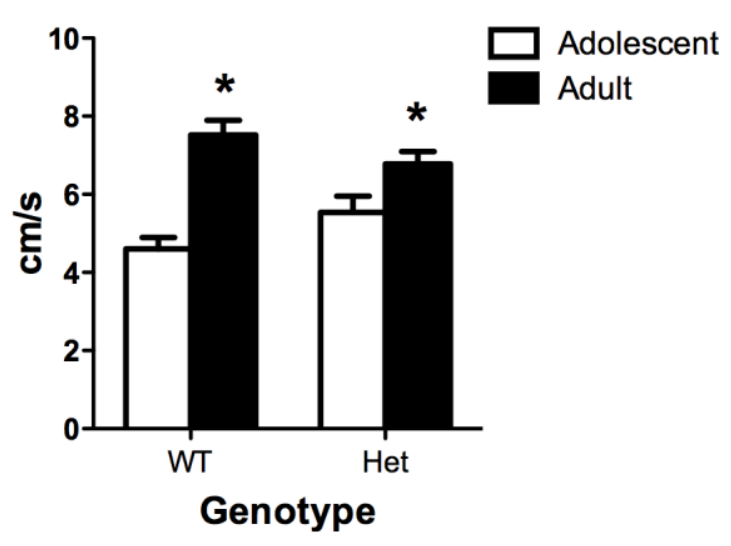




\section{University Library}

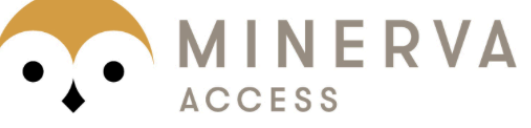

A gateway to Melbourne's research publications

Minerva Access is the Institutional Repository of The University of Melbourne

Author/s:

Kim, JH;Lavan, D;Chen, N;Flores, C;Cooper, H;Lawrence, AJ

Title:

Netrin-1 receptor-deficient mice show age-specific impairment in drug-induced locomotor hyperactivity but still self-administer methamphetamine

\section{Date:}

2013-12-01

\section{Citation:}

Kim, J. H., Lavan, D., Chen, N., Flores, C., Cooper, H. \& Lawrence, A. J. (2013). Netrin-1 receptor-deficient mice show age-specific impairment in drug-induced locomotor hyperactivity but still self-administer methamphetamine. PSYCHOPHARMACOLOGY, 230 (4), pp.607-616. https://doi.org/10.1007/s00213-013-3187-5.

Persistent Link:

http://hdl.handle.net/11343/91068 